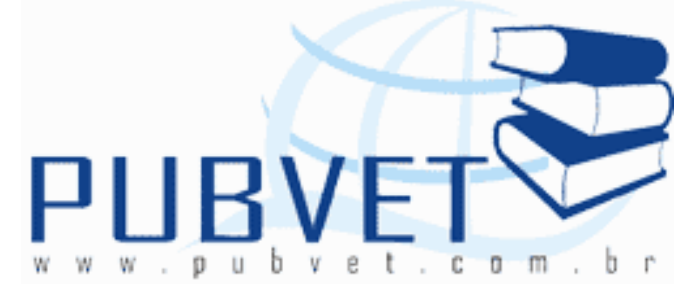

PUBVET, Publicações em Medicina Veterinária e Zootecnia.

Disponível em: <https://doi.org/10.31533/pubvet.v02n11a446>.

\title{
Silagem de cana-de-açúcar como fonte de alimentação de ruminantes
}

\section{Carlos Rosa Godoi ${ }^{1}$ e Edneia Freitas Portilho ${ }^{2}$}

\begin{abstract}
${ }^{1}$ Aluno do Curso de Zootecnia do Centro Federal de Educação Tecnológica de Rio Verde - GO.

${ }^{2}$ Profa: do Departamento de Medicina Veterinária e Zootecnia da FesurvUniversidade de Rio Verde - GO, Mestre em Ciências da Saúde-UNB-Brasilia,DF.
\end{abstract}

\section{Resumo}

No Brasil, ainda que respeitando-se as especificidades de cada região, os alimentos conservados constituem a maior parte da fonte de forragem suplementar. A utilização da cana-de-açúcar na forma de silagem tem sido uma alternativa para contornar os problemas do corte diário, além da praticidade no uso em todo o sistema de produção. O tamanho ideal do corte deve ser de 1 a $2 \mathrm{~cm}$ para qualquer forrageira a ser ensilada. Silos do tipo Trincheiras são os mais comuns nos dias atuais devido a sua facilidade de carregamento, de compactação, de descarregamento e seu custo de construção. O processo de ensilagem consiste em cortar a forragem no campo, picá-la em pedaços e ir colocando a forragem picada no fundo do silo. Após a correta vedação do silo,os microrganismos aeróbios, necessitam de oxigênio 
para sobreviverem, nesta condição, os microrganismos que necessitam de oxigênio para sobreviverem (aeróbios) morrem ou se tornam inativos e começa o desenvolvimento de outra classe de microrganismos os anaeróbios. Esses microrganismos utilizam os açúcares da forragem para produzirem alguns ácidos orgânicos que são responsáveis pela conservação da forragem na forma de silagem.

Palavras-Chaves: forragem, compactação, bactérias.

\title{
Silage from sugar cane as a source of food for ruminants
}

\begin{abstract}
In Brazil, though it is respecting the specificities of each region, the food kept up the largest part of the supplementary source of forage. The use of sugar cane in the form of silage has been an alternative to circumvent the problems of cutting daily, in addition to practical use in the whole production system. The optimum size of the cut should be 1 to $2 \mathrm{~cm}$ for any fodder to be ensiled. Trenches type of silos are the most common nowadays due to its ease of loading, compression, for unloading and their cost of construction. The process is to cut grass for fodder in the field, the white-pieces and go on putting forage bite at the bottom of the silo. After the correct sealing of the silo, the aerobic organisms, need oxygen to survive in this condition, the microorganisms that need oxygen to survive (aerobic) die or become inactive and begin the development of another class of the anaerobic microorganisms. These microorganisms use the sugars of forage to produce some organic acids that are responsible for the conservation of forage as silage.
\end{abstract}

Key Words: Forage, compaction, bacteria. 


\section{INTRODUÇÃO:}

A silagem é a forragem verde, suculenta, conservada por meio de um processo de fermentação anaeróbica. As silagens são guardadas em silos. Chama-se ensilagem o processo de cortar a forragem, colocá-la no silo, compactá-la e protegê-la com a vedação do silo para que haja a fermentação. (CARDOSO \& SILVA, 1995).

O processo de ensilagem não melhora a qualidade do alimento, mas visa, manter a qualidade do material original (VAN SOEST, 1994).

No Brasil, ainda que respeitando-se as especificidades de cada região, os alimentos conservados constituem a maior parte da fonte de forragem suplementar. A ensilagem é o processo de conservação de forragem mais comumente utilizado, principalmente em propriedades produtoras de leite e de criação de bovinos de elite. (SILVA \& BRENADES, 2004).

As perdas durante os processos da fermentação, relacionadas às alterações químico-bromatológicas da forragem ensilada, têm sido enfocadas em vários estudos. Esse tipo de perda depende das características da planta forrageira e está associado às práticas de implantação, manejo e colheita das lavouras e ao sistema de armazenamento. Na produção das silagens, aspectos relacionados ao tamanho de partículas e à altura de colheita de plantas afetam o grau de compactação. NEUMANN, et al. (2007).

Para fornecer silagem de boa qualidade aos animais não basta apenas tomar as devidas precauções no momento de ensilar. Para que a silagem chegue com a mesma qualidade ao cocho dos animais é fundamental estar atento a algumas estratégias importantes após a abertura do silo. (LIMA \& CUNHA, 2006).

A conservação da cana-de-açúcar é normalmente realizada no canavial onde é cortada diariamente conforme as necessidades do rebanho. Entretanto, esta prática de manejo dificulta a utilização em larga escala por sua dificuldade operacional. Esta limitação tem sido contornada com o uso da ensilagem, 
concentrando a mão-de-obra e reduzindo o trabalho e os deslocamentos diários de máquinas na propriedade. FREITAS, et al. (2006).

A utilização da cana-de-açúcar na forma de silagem tem sido uma alternativa para contornar os problemas do corte diário, além da praticidade no uso em todo o sistema de produção. Por sua grande quantidade de carboidratos solúveis, a cana-de-açúcar é altamente susceptível à ação de leveduras. No meio científico tem pesquisado inúmeros aditivos capazes de controlar a população de leveduras e propiciar a redução das perdas decorrentes dos processos fermentativos. QUEIROZ, (2008). Portanto o presente trabalho de revisão tem como objetivo levar até o produtor à importância de ensilar a cana-de-açúcar como fonte de volumoso para oferecer aos ruminantes em época de escassez do ano, com baixo custo.

\section{REVISÃO DE LITERATURA:}

\subsection{Silagem:}

Essa exploração apresenta grande importância para o agronegócio. Estima se que a área destinada à produção esteja em torno de 5,5 milhões de hectares de área plantada, sendo dez por cento desta destinada a produção animal, aproximadamente 30 milhões de toneladas de massa verde. LANDELL, et al. (2002).

A ensilagem tem por objetivo conservar os nutrientes da planta, ou seja, a sua proteína, seus carboidratos (açucares), os lipídeos, minerais, etc. Para isto ensila-se a planta em um ponto que alia muito bem digestibilidade, teor de nutrientes e produção por área. (GOUVEIA \& FILHO, 2008).

O objetivo do processamento (picagem) é facilitar a compactação, bem como, o rompimento das células, permitindo uma atuação imediata dos microrganismos. Quanto menor o tamanho melhor será a compactação e a expulsão do ar. Por outro lado, pedaços muito pequenos $(<0,5 \mathrm{~cm})$ podem ser desfavoráveis para o funcionamento adequado do rúmen. Quanto menor o 
tamanho de partículas maior a compactação da silagem e maior a exposição dos açúcares às bactérias fermentadoras da silagem. (GOUVEIA \& FILHO, 2008).

O tamanho ideal do corte deve ser de 1 a $2 \mathrm{~cm}$ para qualquer forrageira a ser ensilada. É necessário um tamanho menor do corte para forragens mais secas, quando comparadas com forragens mais úmidas. (AMARAL \& BERNADES, 2008).

\subsection{Tipos de Silos:}

O planejamento de volumosos é de extrema importância, assim, para minimizar esses problemas é necessário pensar em alguns fatores. Que tipo de silo eu disponho na propriedade? Quantos animais vão ser alimentados com essa silagem? Por quanto tempo esses animais vão ficar confinados? Os silos mais comuns de serem encontrados são os trincheira, os de superfície e os cilíndricos, havendo em cada um destes, vantagens e desvantagens em seu uso. (AMARAL \& MONTEIRO, 2006).

Silos do tipo cilíndricos são pouco utilizados, devido em grande parte por seu manejo ser difícil, apesar de proporcionar boas condições para a fermentação da forragem. Silos do tipo Trincheiras são os mais comuns nos dias atuais devido a sua facilidade de carregamento, de compactação, de descarregamento e seu custo de construção. Silo de superfície é o mais econômico, e por não haver nenhum tipo de estrutura fixa pode ser feito mais perto do local onde estão os animais, devendo-se atentar em relação a compactação, pois não havendo paredes é necessário um maior tempo de trabalho.

\subsection{Processo de Ensilagem:}

O processo de ensilagem consiste em cortar a forragem no campo, picá-la em pedaços e ir colocando a forragem picada no fundo do silo. A cada camada 
colocada o material deve ser compactado, ou com "pesos de socar", ou com animais pisoteando a forragem ou com trator (cuidado! o pneu do trator deve estar limpo, pois se ele levar terra ou barro para dentro do silo, a fermentação não vai ser boa e haverá perda de silagem). A compactação bem feita é um dos segredos da boa ensilagem. (CARDOSO \& SILVA, 1995).

É uma técnica que consiste em preservar forragens por meio de fermentação anaeróbica, após o seu corte, picagem, compactação e vedação em silos. A prática da confecção de silagem tem sido cada vez mais comum na produção de gado de corte, principalmente em regiões com exploração pecuária mais tecnificada, onde a procura por melhores índices zootécnicos e rentabilidade econômica tem levado grande número de produtores, que utilizam o confinamento, a adotarem sistematicamente essa prática. SILVA, (2001).

A ensilagem é uma boa opção para o aproveitamento do excesso de forragem produzida durante a estação de maior crescimento das plantas forrageiras, garantindo a alimentação adequada na época das secas. Em todo o mundo, a conservação de alimentos, principalmente de volumosos, tem sido utilizada como uma técnica que permite a utilização desses alimentos em qualquer época do ano. LINHARES, et al. (2005).

Na produção das silagens, aspectos relacionados ao tamanho de partículas e à altura de colheita de plantas afetam o grau de compactação. NEUMANN, et al. (2007).

Quanto menor a partícula e maior a altura de colheita, melhor a compactação e,conseqüentemente, a condição de anaerobiose, que é decisiva no processo de conservação. SENGER, et al. (2005).

Quando se coloca a forragem no interior do silo e procede-se a compactação, elimina-se grande parte do oxigênio existente entre as partículas de forragem. (LIMA \& CUNHA, (2006).

A degradação aeróbia da silagem pode ser causada por fungos e bactérias acetogênicas que utilizam açúcares residuais e produtos da fermentação, como 
o ácido láctico, como substratos, elevando a temperatura em até $45^{\circ} \mathrm{C}$ (ROTZ \& MUCK, 1994).

As bactérias responsáveis pela produção de ácido lático são aquelas dos gêneros Lactobacillus e Pediococcus, que sendo microrganismos benéficos, são importantes para a qualidade do produto produzido. O clostridio é uma bactéria indesejável, responsável pela produção de ácido butírico e pela deterioração da silagem. Este microrganismo é capaz de converter o lactato em butirato, além de atacarem as proteínas. (GOUVEIA \& FILHO, 2008).

\subsection{Cobertura da Silagem:}

Após a correta vedação do silo, os microrganismos aeróbios (necessitam de oxigênio para sobreviverem) que acompanham a forrageira se encarregam de consumir o restante do oxigênio. Com o término do oxigênio, a condição no interior do silo se torna anaeróbia (sem oxigênio). Nesta condição, os microrganismos que necessitam de oxigênio para sobreviverem (aeróbios) morrem ou se tornam inativos e começa o desenvolvimento de outra classe de microrganismos, os anaeróbios (não necessitam de oxigênio para sobreviverem). Esses microrganismos (anaeróbios) utilizam os açúcares da forragem para produzirem alguns ácidos orgânicos que são responsáveis pela conservação da forragem na forma de silagem. E se não houver entrada de ar e, ou água no interior do silo, a silagem poderá ser armazenada por longo período. (LIMA \& CUNHA, 2006).

Todos os ácidos orgânicos se combinam para acidificar a silagem, entretanto, o ácido lático é o mais importante, pois é aquele que apresenta maior constante de dissociação, sendo o ácido mais forte, responsável pelo abaixamento efetivo do pH para 3,8 a 4.2. (GOUVEIA \& FILHO, 2008). 


\subsection{Desensilagem (abertura da silagem):}

O processo de desensilagem é afetado principalmente pela desestruturação da massa, com conseqüente entrada de $\mathrm{O}_{2}$ e ativação dos processos químicos, físicos e microbiológicos que atuam em detrimento ao valor nutritivo da silagem McDonald, et al. (1991) NEUMANN, et al. (2002).

Após a abertura do silo, a silagem ficará exposta ao ar e, nesta condição, os microrganismos aeróbios (aqueles que necessitam de oxigênio para sobreviverem) voltam a atuar. Esses microrganismos são prejudiciais à qualidade da silagem, pois são agentes responsáveis pela degradação da proteína e transformam o ácido lático (fundamental para preservação da silagem) em ácido butírico. A presença de ácido butírico na silagem é indicativa de fermentação inadequada, ou seja, é indicativa de perda do valor nutritivo da silagem. (LIMA \& CUNHA, 2006).

Os procedimentos de "desensilagem" podem afetar a qualidade nutritiva do produto até seu consumo. A silagem sem a presença de oxigênio e com acúmulo de ácido láctico resulta na diminuição do $\mathrm{pH}$, na inibição do metabolismo microbiano e na preservação dos nutrientes. Entretanto, quando exposta ao ar, certos microrganismos oportunistas se tornam metabolicamente ativos, produzem calor e consomem nutrientes da silagem. RANJIT \& KUNG Jr. (2000).

A adoção de algumas estratégias básicas no manejo do painel do silo certamente evitará perdas e prejuízos desnecessários. Exige, apenas, cuidado, zelo e capricho na retirada e utilização da silagem. Sendo assim, após a abertura do silo, diariamente, deve-se descartar as partes estragadas (escuras, podres) e as partes com presença de mofo (fungadas). Silagens com essas características possuem elementos tóxicos que poderão causar sérios problemas à saúde dos animais, inclusive morte. A camada de silagem a ser retirada do silo, diariamente, não deve ser inferior a $20 \mathrm{~cm}$. Deve-se retirar a silagem de forma que o painel do silo seja mantido liso, ou seja, não devem ser escavados buracos ou escadas na silagem. (LIMA \& CUNHA, 2006). 


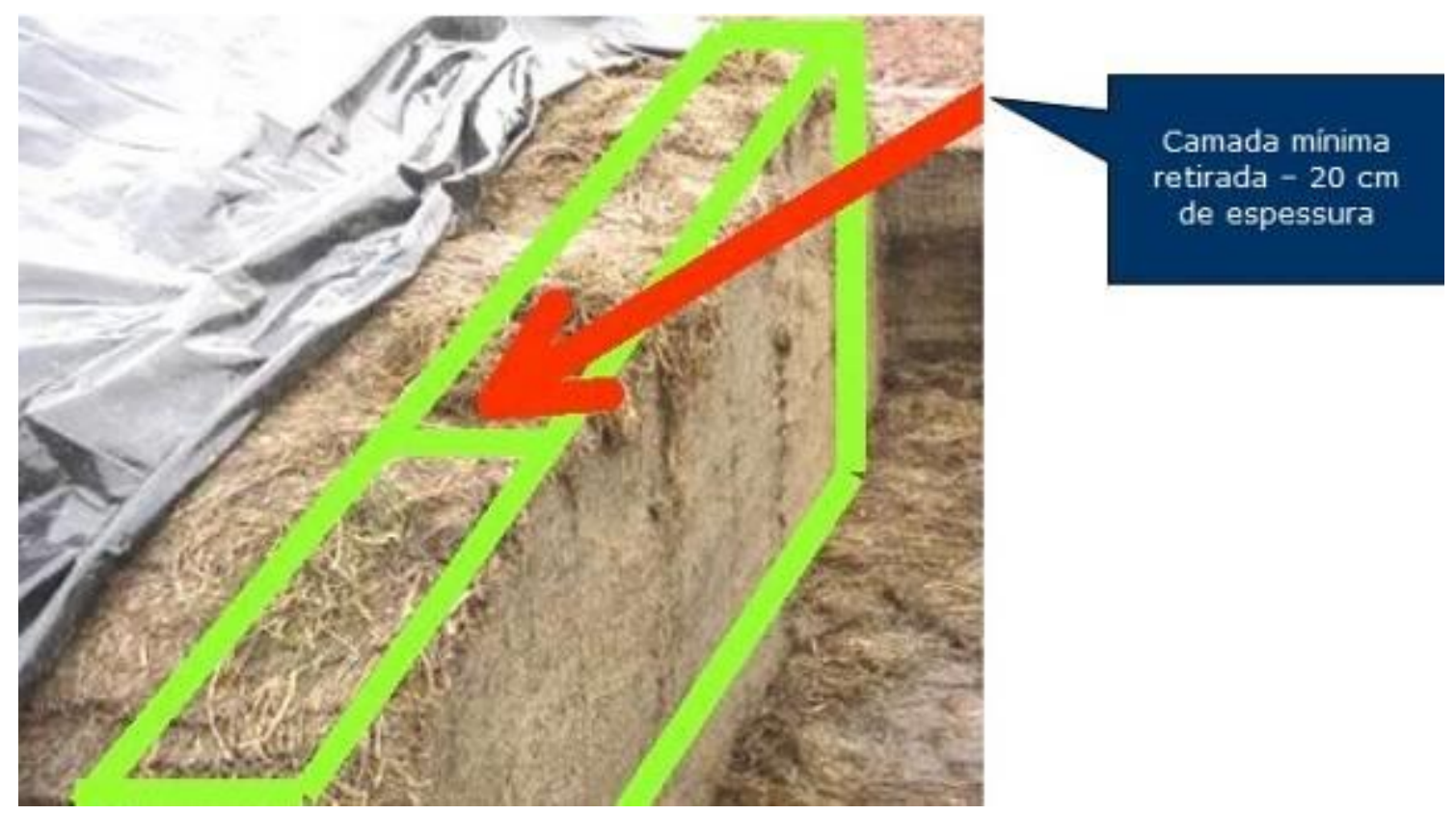

Fonte: LIMA \& CUNHA, 2006.

Deve-se evitar construir silos muito grandes. É importante remover um mínimo de 15 a $20 \mathrm{~cm}$ por dia de silagem da face do silo, uniformemente. (GOUVEIA \& FILHO, 2008).

Aproximadamente 40 dias após o fechamento do silo, a silagem poderá ser fornecida aos bovinos. Se tiver sido bem feita e o silo não for aberto, a silagem pode conservar-se por mais de 1 ano. Uma vez aberto o silo, a cada dia deve ser retirada uma fatia de no mínimo $15 \mathrm{~cm}$. CARDOSO \& SILVA, 1995).

\subsection{Cana de Açúcar:}

O Brasil como país tropical, apresenta excelentes condições para a exploração de ruminantes em pastagens, porém em determinados períodos do ano, a dificuldade de adquirir alimentos volumosos em regiões áridas e semiáridas, em épocas secas, torna-se uma árdua e difícil tarefa para muitos 
produtores rurais. A cana-de-açúcar, nome comum de uma herbácea vivaz, planta da família das gramíneas, espécie Saccharum officinarum, originária da Ásia Meridional, é muito cultivada em países tropicais e subtropicais para obtenção do açúcar, do álcool e da aguardente, devido a sacarose contida em seu caule, formado por numerosos nós. O mesmo autor relata que, Historicamente a cana-de-açúcar é um dos principais produtos agrícolas do Brasil, sendo cultivada desde a época da colonização. O país também assume a posição de maior produtor mundial de cana-de-açúcar e açúcar e exportador de açúcar e álcool, sendo sua área cultivada de, aproximadamente, 6,5 milhões de hectares. CASTRO, et al. (2008).

A cana-de-açúcar se caracteriza por ser uma forrageira com elevada capacidade de produção de matéria seca e carboidratos de rápida degradabilidade ruminal por unidade de área. O consumo de cana é normalmente inferior ao de outras gramíneas com o mesmo teor de fibra e detergente neutro (FDN). A baixa porcentagem de proteína e a baixa digestibilidade da fibra inviabilizam a utilização da cana-de-açúcar como ingrediente dietético único. (PEREIRA \& SAENZ, 2004).

A cana de açúcar, assim como outras forrageiras, possui as principais características necessárias para a produção de silagem: teor de matéria seca (MS) em torno de 25 a 30\%, teor de carboidratos solúveis (CHOs) próximos a $10 \%$ da matéria natural ( $\mathrm{MN}$ ) e poder tampão que permite a queda do $\mathrm{pH}$ para valores próximos a 3,5. FREITAS, et al. (2006).

A utilização da cana-de-açúcar como recurso forrageiro para a minimização dos efeitos da entressafra das pastagens vêm crescendo ano a ano. O dogma de ser considerado um volumoso restrito a animais de baixo potencial produtivo, quer seja para leite ou carne, preconizado por pesquisadores e técnicos nos idos dos anos 70 e 80, vem sendo substancialmente renegado. Encontrava-se na literatura citações taxando a utilização da cana-de-açúcar para vacas com produção até $10 \mathrm{~kg}$ leite/dia. Atualmente, trabalhos de pesquisa e experiências práticas mostram que a cana-de-açúcar pode e deve ser utilizada para animais de alta produção. Vale 
lembrar que suas limitações nutricionais, principalmente conteúdo de proteína e minerais devem ser considerados na formulação da ração. (SIQUEIRA \& BERNADES, 2005).

O cultivo de cana-de-açúcar caracteriza-se como uma das mais importantes atividades do agronegócio brasileiro. O Brasil se destaca como maior produtor mundial de cana-de-açúcar, com produção de 423 milhões de toneladas na última safra (2004-2005). Contudo, a planta não é importante somente para o setor industrial do açúcar e do álcool, uma vez que relatos de 1913 já mencionavam seu uso como fonte de volumoso suplementar aos animais. QUEIROZ, (2008).

\subsection{Preparo do Solo e Plantio da Cana:}

A cana-de-açúcar possui um sistema radicular diferenciado em relação à exploração das camadas mais profundas do solo quando comparado com o sistema radicular das demais culturas, principalmente as anuais. Os solos eutróficos são mais produtivos por apresentarem saturação por bases superior a $50 \%$ em profundidade, fazendo com que a raiz explore maior volume de solo, possibilitando maior aporte de água. Dessa forma, a absorção de nutrientes é favorecida e a planta passa a suportar veranicos com mais facilidade. STAUT, (2008).

Apesar da cana-de-açúcar não apresentar grandes respostas ao uso da calagem, é importante o conhecimento das quantidades de cálcio e magnésio para a sua correção. VIANA, et al.(2008).

Fica claro que para se obter produtividades satisfatórias, é necessário proceder à recuperação da fertilidade dos solos tanto nas camadas superficiais como também em profundidade, quando estes não apresentarem condições ideais para o cultivo da cana, Com a melhoria do perfil de solo em relação à fertilidade, observa-se que solos mais arenosos podem atingir produtividades semelhantes a dos argilosos. Corrigindo-se as limitações químicas, o cultivo da 
cana-de-açúcar em uma mesma área pode se prolongar por um bom tempo. STAUT, (2008).

Em áreas de baixada, a primeira aração deve ser feita mais rasa, aos 60 dias antes do plantio, com aproximadamente $15 \mathrm{~cm}$, para a destruição dos restos culturais da atividade anterior, ou através de uma gradagem pesada. Por ocasião do plantio, a segunda aração deve ser mais profunda, aproximadamente $30 \mathrm{~cm}$, fazendo-se duas gradagens para destorroamento do solo. O plantio da cana não irrigada é feito em dois períodos: entre janeiro e março para a cana de ano e meio e entre outubro e dezembro para a cana de ano. Com irrigação, os períodos podem ser de janeiro a abril e de setembro a dezembro. a cana-planta deverá ter idade média de 11 meses, devendo ser proveniente de viveiros, e colhida crua, com palha. Antes do plantio, faz-se a despalha completa e corta-se em toletes com três gemas, tendo-se o cuidado de eliminar os brocados ou doentes. Esse sistema deve ser utilizado quando as condições da cana-planta, solo e clima forem desfavoráveis. Sob condições normais, o sistema de plantio com a cana inteira, despalhada e cortada no sulco com três gemas, também pode ser utilizado, poupando mão-de-obra e aumentando o rendimento dos serviços. Gastam-se, em média, 8 toneladas de cana-planta/ha. A sulcação deve ser feita mecanicamente, à profundidade de $25 \mathrm{~cm}$. Após a colocação no fundo do sulco, faz-se a sua cobertura com uma camada de solo de 6 a $8 \mathrm{~cm}$. Em solos mais úmidos e com altas temperaturas, a camada deve ser de $6 \mathrm{~cm}$. O espaçamento entre sulcos deve ser de 1,00 a $1,50 \mathrm{~m}$, dependendo da variedade utilizada. VIANA, et al.(2008).

\section{8 Época do Corte:}

O ponto de colheita envolve a maturidade da planta e o seu conteúdo de umidade. A umidade adequada, no momento da ensilagem, favorece a compactação, acelerando a transição da silagem para um ambiente anaeróbico. A colheita na maturidade correta assegura quantidade de 
carboidratos fermentáveis adequada para as bactérias da silagem e valor nutricional ótimo para o rebanho. (GOUVEIA \& FILHO,2008).

O período mais recomendado é a época da seca, porque é nele que a cana apresenta maior teor de açúcares. A colheita pode ser manual ou mecânica. (EVANGELISTA \& LIMA. 2003).

A cana-de-açúcar sempre deve ser colhida crua, principalmente para o uso na alimentação animal. O corte para forragem é feito rente ao solo, procurando-se manter toda a parte verde da planta. VIANA, et al.(2008).

\subsection{Dimensionamento do Silo:}

(AMARAL \& MONTEIRO, 2006). Para silos trincheira, que geralmente possuem formato de um trapézio com a base inferior menor que a base superior $o$ cálculo é realizado da seguinte forma: Exemplo:

Um silo com $4 \mathrm{~m}$ de base inferior(b), $5 \mathrm{~m}$ de base superior (B), $2 \mathrm{~m}$ de altura (A) e $10 \mathrm{~m}$ de comprimento (C), tem 0 seguinte volume: $[(B+b) / 2] \times A=4,5 \times 2=9 \mathrm{~m} 2$ (área da face de silo); $9 \mathrm{~m} 2 \times 10 \mathrm{~m}=90 \mathrm{~m} 3$ (volume total do silo) $\mathrm{Se} O$ silo possuir bases iguais $\left(\begin{array}{lll}4 & \mathrm{~m}\end{array}\right)$ volume será: $(B \times A)=4 \mathrm{~m} \times 2 \mathrm{~m}=8 \mathrm{~m} 2$ (área da face do silo) $8 \mathrm{~m} 2 \times 10 \mathrm{~m}=80 \mathrm{~m} 3$ (volume total do silo)

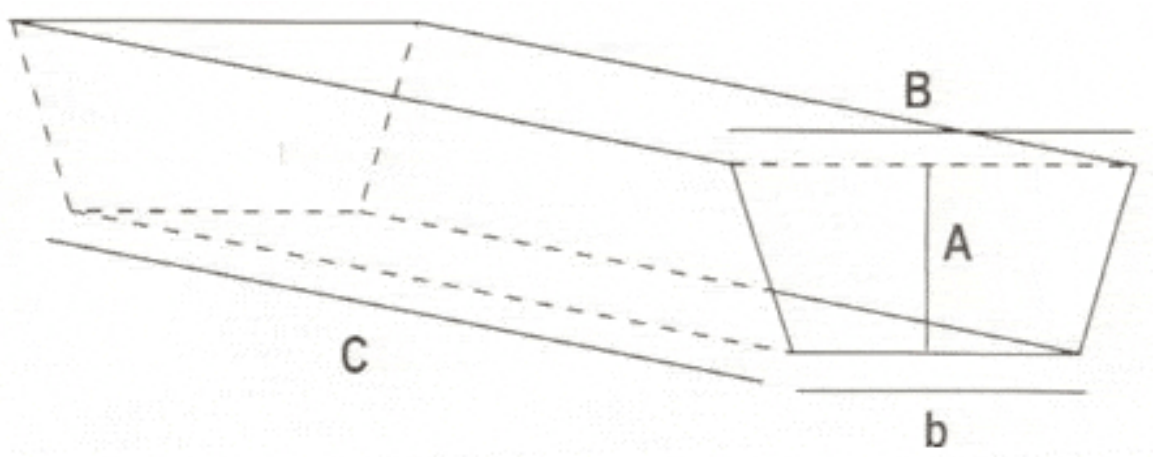


Godoi, C.R. e Portilho, E.F. Silagem de cana-de-açúcar como fonte de alimentação de ruminantes. PUBVET, Londrina, V. 2, N. 45, Art\#446, Nov2, 2008.

Silo do tipo superfície (trapezoidal) pode ter seu volume estimado da mesma maneira do silo trincheira, mais será difícil chegar a uma estimativa precisa.

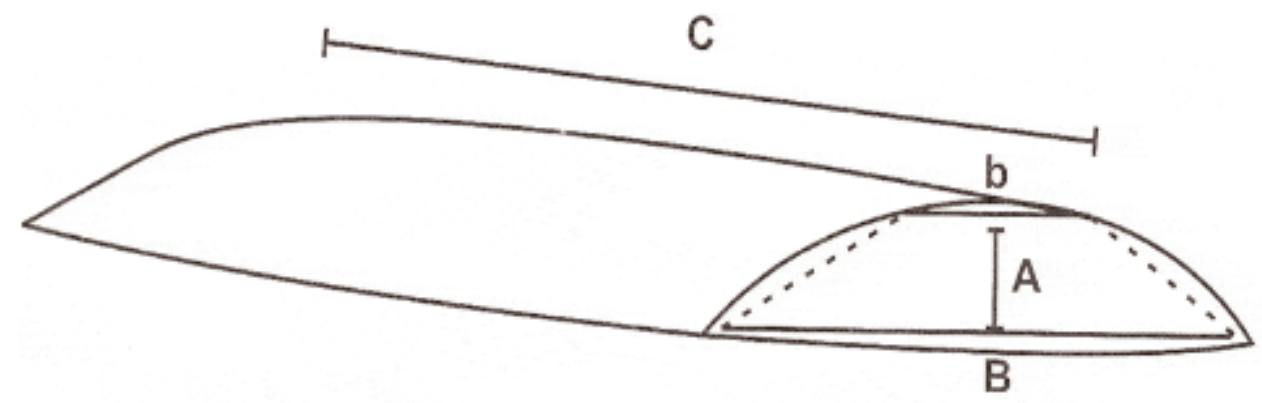

Dimensões do silo-superficie

O cálculo para silos cilíndricos depende da fórmula $(n \times r 2)$ e multiplicá-la pela altura do silo.

Exemplo: Um silo com raio de 1,5 m ( $\mathrm{r}$ ) e 10 metros de altura $(A)$, seu volume será:

$\Pi \times(1,5 \mathrm{~m}) 2=3,14 \times 2,25 \mathrm{~m} 2=7,07 \mathrm{~m} 2$ ( área a face do silo) $7,07 \mathrm{~m} 2 \times 10 \mathrm{~m}=70,70 \mathrm{~m} 3$ (volume total do silo)

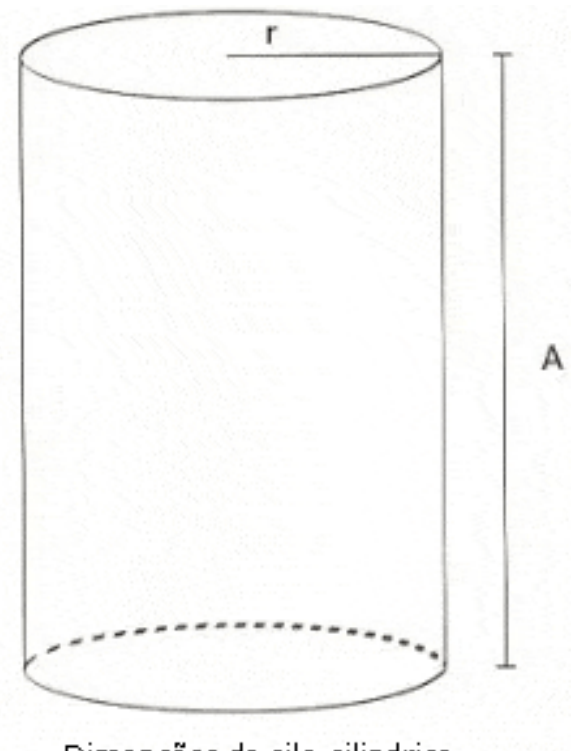

Dimensões do silo-cilindrico

Multiplicando-se o resultado do volume pela densidade de compactação, será obtido a quantidade de forragem a ser ensilada. 
Volume do silo $(90 \mathrm{~m} 3) \times$ densidade constante $(620 \mathrm{Kg} / \mathrm{m} 3$ ) - (importante salientar que para diferentes culturas, diferentes teores de MS e diferentes graus de compactação existe variação na densidade da forragem). $90 \mathrm{~m} 3 \times 0,62 \mathrm{t} / \mathrm{m} 3=55,8 \quad \mathrm{t}$ de MV Supondo um rebanho de vacas leiteiras (50 animais), com média de peso vivo de $450 \mathrm{Kg}$, comendo $2,5 \%$ do peso vivo em matéria seca da ração total $(11,25$ $\mathrm{Kg}$ de MS), com relação volumoso:concentrado 60:40, a quantidade de silagem para cada animal é de $6,75 \mathrm{Kg}$ de $\mathrm{MS}$, se o alimento conservado apresenta $28 \%$ de MS, a quantidade de material verde oferecido a cada animal será de $24,11 \mathrm{Kg}$ de silagem fresca. Se a necessidade de volumoso conservado for de 180 dias: 1 vaca: $24,11 \mathrm{Kg}$ silagem/dia/vaca 50 vacas: $24,11 \times 50=1205,5 \mathrm{Kg}$ silagem/dia 50 vacas em 180 dias: $1205,5 \times 180=217$ t. Com essas informações, pode-se estimar a quantidade de silagem a ser utilizada durante o ano, porém a quantidade estocada deverá ser maior que o consumo dos animais, devido às perdas que ocorrem na ensilagem, processo fermentativo, retiradaefornecimento. Para o exemplo anterior, assumindo perdas totais de $15 \%$, com consumo previsto de 217 t de silagem fresca, será necessário ensilar: Quantidade a ser consumida: 217 t de MV "Quantidade a serensilada: 217t/(100-\%perdas). Assim: 217t/(100-15) = 255 t MV "Pode-se observar que com um planejamento e cálculos simples o produtor tem a capacidade de estimar a quantidade de volumoso conservado, que será utilizado durante o período seco e o tamanho do silo que será necessário, podendo optar pelo silo que mais se adequar a suas condições.

\section{Conclusão:}

O processo de silagem é importante para minimizar os efeitos entressafra das pastagens, e a cana-de-açúcar é uma forragem suplementar de rápida degradabilidade ruminal, e características necessárias para produção da silagem, matéria seca e excelente teor de carboidrato com boa patabilidade. Após a vedação da silagem, sabemos que as bactérias são responsáveis pela 
Godoi, C.R. e Portilho, E.F. Silagem de cana-de-açúcar como fonte de alimentação de ruminantes. PUBVET, Londrina, V. 2, N. 45, Art\#446, Nov2, 2008.

qualidade da silagem e com adição de inoculantes microbianos é uma boa opção no processo fermentativo para produzir rapidamente ácido lático.

\section{REFERÊNCIA BIBLIOGRAFICA}

AMARAL, R. C. do.; BERNADES, T. F. Silagem: Quatorze perguntas, quatorze e respostas, 2008.

AMARAL, R. C. do.; MONTEIRO, R. R. Planejamento da quantidade de silagem e dimensionamento de silo, 2006.

CANA-DE-AÇÚCAR RESPOSTA TÉCNICA, VIANA,A. R.; FERREIRA, M.; FILHO, S. B. R.; FILHO, J. R. Disponível em:< http://www.pesagro.rj.gov.br/cana.html >. Acesso em: 07 set 2008.

CARDOSO, E.G.;SILVA, J.M. Embrapa gado de corte divulga silos, silagem e enslagem, Campo Grande, MS,1995 n02.

CASTRO,L. B. B. N. de .; OLIVEIRA, L. A. de.; MOREIRA, R. F.; MURTA, R. M. Bagaço da canade-açúcar para alimentação de ruminantes. PUBVET, V. 2, N. 30, Jul 5, ISSN 1982-1263, 2008.

EVANGELISTA, A. R. \& LIMA, J. A. Produção de Silagens Alternativas. Lavras: UFLA/FAEPE, 2003.

FERNANDES, A. Ficha técnica 29 Ministério da Agricultura, do Desenvolvimento Rural e das Pescas. Primeira edição agosto de 1998. Edição on-line 2007.

FREITAS, A.W.P.; PEREIRA, J.C.; ROCHA, F.C.; COSTA, M.G.; LEONEL, F.P.; RIBEIRO, M.D. Avaliação da qualidade nutricional da silagem de cana de açúcar com aditivos microbianos e enriquecida com resíduo de colheita de soja. Revista Brasileira de Zootecnia. v. 35. n. 1. p. 3847. 2006.

GOUVEIA,L. F.; FILHO,R. A. Produção de Silagem de Qualidade. Disponível em: < http://www.beefpoint.com.br/bn/hotsites/Chr-hansen/inoculantes/prod sil qualidade.pdf >. Acesso em: 07 set 2008.

LANDELL, M. G. A.; CAMPANA, M. P.; RODRIGUES, A. A.; CRUZ, G.M.; ATISTA, L. R. R.; FIGUEIREDO, P.; SILVA, M. A.; BIDDA, M. A.; ROSETTO, R.; ARTINS, A. L. M.; GALLO, P. B.; KANTHOCK, R. A. D.; CAVICHIOLO, J. C.; ASCONCELOS, A. C. M.; XAVIER, M. A. A variedade IAC86-280 como nova opção de cana de açúcar para fins forrageiros: Manejo e uso na alimentação animal. Boletim Técnico - IAC 193. Serie Tecnologia APTA. Instituto Agronômico de Campinas (IAC). Campinas, abril de 2002. 36p.

LIMA, J. A. de, CUNHA, E. A. Silagem: Capricho na retirada é fundamental para colocar no cocho silagem de boa qualidade. 2006. Artigo em Hypertexto. Disponível em: <http://www.infobibos.com/Artigos/2006 3/Silo/index.htm>. Acesso em: 23 Jul 2008.

LINHARES,P. C. F.; MARACAJÁ,P. B.; FILHO,J. L.; VASCONCELOS,S. H. L.; NUNES, G. H. S. Inclusão de jitirana na composição química bromotológica de silagem de milho. CAATINGA, Mossoró-RN, v.18, n.2, p.117-122, abr./jun. 2005. 
Godoi, C.R. e Portilho, E.F. Silagem de cana-de-açúcar como fonte de alimentação de ruminantes. PUBVET, Londrina, V. 2, N. 45, Art\#446, Nov2, 2008.

MCDONALD, P.; HENDERSON, N.; HERON, S. The biochemistry of silage. 2. ed. Marlow: Chalcombe, 1991. 339p.

NEUMANN,M.; MUHLBACH,P. R. F.; NORNBERG, J. L.; RESTLE, J.; OST, P. R. Efeito do tamanho de partícula e da altura de colheita das plantas de milho (Zea mays L.) sobre as perdas durante o processo fermentativo e o período de utilização das silagens, R. Bras. Zootec. v.36 n.5 Viçosa set./out. 2007.

PEREIRA, M. N. e SAENZ, E. A. C. Algumas considerações sobre a velha cana com uréia. 2004. Disponível <http://www. milkpoint.com.br/?noticiaID $=19506 \& a c t A=7 \&$ areaID $=61 \&$ secaoID $=176$ Acesso em: 04 jul 2008.

QUEIROZ, O. C. M.; NUSSIO, L. G.; SCHMIDT, P.; RIBEIRO,J. L.; SANTOS, M. C.; ZOPALLATT,M. Silagem de cana-de-açúcar Comparada a fontes tradicionais de volumosos suplementares no desempenho de vacas de alta produção, R. Bras. Zootec. v.37 n.2 Viçosa fev. 2008.

RANJIT, N. K.; KUNG Jr., L.The effect of Lactobacillus buchneri, Lactobacillus plantarum, or a chemical preservative on the fermentation and aerobic stability of corn silage. Journal of Dairy Science, v. 83, n. 3, p. 526-535, 2000.

ROTZ, C.A.; MUCK, R.E. Changes in forage quality during harvest and storage. In: FAHEY, G.C. et al. (Eds). Forage quality, evaluation, and utilization. Madison: University of Nebraska, 1994. p.828-868.

SENGER, C. C. D.; MUHLBACH, P. R. F.; SÁNCHEZ, L. M. B. et al. Composição química e digestibilidade "in vitro" de silagem de milho com distintos teores de umidade e níveis de compactação. Ciência Rural, v.35, n.6, p.1393-1399, 2005.

SILVA, M. J. DA. Silagem de forrageiras tropicais, EMBRAPA, Gado de Corte Divulga. Campo Grande, MS, ago. 2001 n० 51.

SILVS, Z.F.; BERNADES, T.F. A silagem de milho é a melhor opção de volumoso suplementar. 2004.

SIQUEIRA,G. R.; Bernardes, T. F. Cana-de-açúcar: um breve histórico de sua utilização, 2005.

STAUT, L.A. Condições dos solos para o cultivo de cana-de-açúcar. 2006. Artigo em Hypertexto. Disponível em: <http://www.infobibos.com/Artigos/2006 2/CanaSolo/index.htm>. Acesso em: 6 Agos 2008.

VAN SOEST, P.J. Nutritional ecology of the ruminant. Ithaca: Cornell University, 1994. 476p. 